\title{
SUPERAÇÃO DE DORMÊNCIA E TEMPERATURAS PARA GERMINAÇÃO DE SEMENTES DE Acacia caven (Mol.) Mol. (ESPINILHO) ${ }^{1}$
}

\author{
TAIANE ACUNHA ESCOBAR 2 , VANESSA MARQUES PEDROSO 3 , ROSELAINE NEVES BONOW 4 , \\ EDUARDO BRUM SCHWENGBER ${ }^{5}$
}

\begin{abstract}
RESUMO - O espinilho (Acacia caven (Mol.) Mol.) é uma planta nativa do sudoeste do Rio Grande do Sul, Brasil, e não existe metodologia eficiente para a análise de sementes da espécie. Desta forma o objetivo do trabalho foi avaliar tratamentos para a superação da dormência das sementes e temperaturas para a condução do teste de germinação de A. caven. Foram utilizados cinco tratamentos na superação da dormência: testemunha (T1); imersão das sementes em água a $40{ }^{\circ} \mathrm{C}$ por $24 \mathrm{~h}$ (T2); imersão das sementes em hipoclorito de sódio a $0,5 \%$ por $24 \mathrm{~h}$ (T3); escarificação mecânica com lixa de água $\mathrm{n}^{\circ} .80$ (T4) e corte na região oposta à micrópila (T5). Para a germinação utilizaram-se as temperaturas constantes de $20^{\circ} \mathrm{C}, 25^{\circ} \mathrm{C}$ e $30^{\circ} \mathrm{C}$, fotoperíodo de $12 \mathrm{~h}$, em substrato de papel (SP). O delineamento experimental foi o inteiramente casualizado com quatro repetições de 50 sementes. Os dados expressos em porcentagem foram transformados em arcsen $\sqrt{x / 100}$ e as médias comparadas pelo teste de Tukey a $5 \%$ de probabilidade. Os tratamentos mais eficientes para superação da dormência foram o T4 e T5. A maior porcentagem de germinação foi obtida a $30{ }^{\circ} \mathrm{C}$. $\mathrm{O}$ teste de germinação pode ser finalizado com 7 dias e a primeira contagem da germinação no $5^{\circ}$ dia.
\end{abstract}

Termos para indexação: Espécie florestal, temperatura, luz, plântulas, germinação.

\section{OVERCOMING DORMANCY AND TEMPERATURES FOR SEED GERMINATION OF Acacia caven (Mol.) Mol.}

\begin{abstract}
Acacia caven (Mol.) Mol. is a native species from southwest Rio Grande do Sul state, Brazil, and there is no effective methodology for analyzing its seeds. The objective of this study was to evaluate treatments for overcoming dormancy and temperatures for carrying out germination tests for $A$. cavens seed. Five treatments were used to overcome dormancy: control $\left(\mathrm{T}_{1}\right)$; immersion of seeds in water at $40{ }^{\circ} \mathrm{C}$ for $24 \mathrm{~h}\left(\mathrm{~T}_{2}\right)$; immersion of seeds in $0.5 \%$ sodium hypochlorite for $24 \mathrm{~h}\left(\mathrm{~T}_{3}\right)$; mechanical scarification with water sandpaper $\mathrm{n}^{\circ} .80\left(\mathrm{~T}_{4}\right)$ and incision in the region opposite to the micropyle $\left(\mathrm{T}_{5}\right)$. The germination tests were carried out at constant temperatures of $20^{\circ} \mathrm{C}, 25^{\circ} \mathrm{C}$ and $30^{\circ} \mathrm{C}$, under artificial light, on a paper substrate. The experimental design was completely randomized with four replications of 50 seeds. The data as percentages were transformed into arcsine $\sqrt{x / 100}$ and the means compared by Tukey's test at
\end{abstract}

${ }^{1}$ Submetido em 22/12/2009. Aceito para publicação em 11/03/2010. Trabalho de Conclusão do Curso de Graduação em Ciências Biológicas do primeiro e segundo autores, apresentado à PUCRS Campus Uruguaiana. BR $472 \mathrm{Km} 7$, Caixa Postal 249, Uruguaiana-RS.

${ }^{2}$ Bióloga - Graduanda em Tecnologia em Aquicultura da Universidade Federal do Pampa, UNIPAMPA, Uriguaiana, RS, taianeescobar@hotmail. com.

${ }^{3}$ Bióloga Pós-Graduanda em Ecologia Aquática Costeira da Universidade
Federal do Rio Grande, FURG, Rio Grande, RS vavimp@yahoo.com.br.

${ }^{4}$ Eng. Agr., Dr. em Ciências - Área de atuação em Tecnologia de Sementes, RIOGRATEC, Tecnologia para Sementes e Plantas LTDA, Cachoeirinha, RS, roselaine.bonow@gmail.com.

${ }^{5}$ Zootecnista. Dr. em Ciências Biologias -Área de atuação em Genética, Universidade Federal do Pampa, UNIPAMPA, Dom Pedrito, RS, duduru@ hotmail.com. 
the $5 \%$ probability level. The most efficient treatments for overcoming dormancy were the $\mathrm{T} 4$ and the T5. The highest germination was obtained under a constant temperature of $30^{\circ} \mathrm{C}$. The germination test can be finalized after seven days and first count on the fifth day.

Index terms: Forest species, temperature, light, seedlings, germination.

\section{INTRODUÇÃO}

Acacia caven (Mol.) Mol. é uma espécie nativa da região extra-tropical da América do Sul, sendo encontrada na região central do Chile, centro-leste da Argentina, Paraguai, Uruguai (Marchiori, 1992) e na região campestre do oeste do estado do Rio Grande do Sul, no Brasil (Rambo, 1966).

$\mathrm{O}$ gênero Acacia pertence à família Leguminosae, subfamília Mimosoideae, e compreende várias espécies, dentre as quais $A$. caven, A. bonariensis e A. farnesiana.

Acacia caven pode ser usada como opção em sistemas agrossilvopastoris para a proteção dos animais no campo, evitando sua exposição ao sol e calor excessivo da região da campanha (Joffre et al., 1988; Trejo et al., 1999). É utilizada em práticas de conservação do solo e controle de erosão e Saraiva et al. (2005) atestam que a espécie tem importância como pioneira na formação de ambientes, no qual cria condições favoráveis para o desenvolvimento de outras espécies. Apresenta, também, um sistema radicular profundo, aproveitando os nutrientes de camadas do solo onde as plantas forrageiras não têm acesso (Ovalle e Avendaño, 1984).

As sementes de $A$. caven são ricas em proteínas e carboidratos, podendo ser utilizadas como fonte nutricional para uso humano e animal (Cavada et al., 1996). A madeira pode ser usada para produção de carvão vegetal devido à alta qualidade de sua lenha. Suas flores podem ser usadas na fabricação de perfumes (Correa, 1984).

$\mathrm{Na}$ maioria das espécies florestais a dormência de sementes é um fato comum, sendo esta, em condições naturais de grande valor por ser um mecanismo de sobrevivência da espécie. No entanto, passa a ser um problema quando as sementes são utilizadas para a produção de mudas em razão do longo tempo necessário para a germinação, ficando as mesmas sujeitas a condições adversas, com grandes possibilidades de ataques de fungos, o que acarreta grandes perdas (Borges et al., 1982). Nesse sentido, Ledo (1979) afirma que cerca de $2 / 3$ das espécies florestais apresentam sementes com dormência.

A ocorrência de sementes duras está associada às espécies de diversas famílias botânicas, sendo mais frequentes em leguminosas (Popinigis, 1985). A dormência pode ser ocasionada por vários fatores como impermeabilidade do tegumento à água e aos gases, embriões imaturos ou rudimentares, exigências especiais de luz ou de temperatura, presença de substâncias promotoras ou inibidoras de crescimento, entre outras (Torres e Santos, 1994; Carvalho e Nakagawa, 2000).

Há vários tratamentos pré-germinativos que permitem a superação da dormência das sementes de leguminosas, como o uso de ácidos fortes, a imersão em solventes (água, álcool, etc.), a escarificação mecânica e o choque térmico (Popinigis, 1985; Brasil, 1992).

Os métodos de análise em laboratório têm sido estudados e desenvolvidos para permitir uma germinação regular, rápida e completa da maioria das amostras de sementes de uma determinada espécie (Brasil, 1992). O teste de germinação é de fundamental importância para os testes de controle de qualidade de sementes, sendo que as condições ótimas para a espécie devem ser padronizadas para que os resultados destes possam ser reproduzidos e comparados, dentro dos limites tolerados pelas Regras para Análise de Sementes (Brasil, 1992).

Com o aumento da demanda por madeira, e devido à necessidade de recuperação de solos degradados e de restauração florestal, o consumo de sementes de espécies arbóreas aumentou consideravelmente, motivando inclusive a realização de pesquisas com sementes dessas espécies (Santos e Aguiar, 2000).

Os estudos direcionados ao conhecimento específico dos aspectos morfológicos da germinação de sementes de uma espécie, além de contribuirem em sua propagação, tornamse fundamentais para o melhor planejamento e tratamento silvicultural das espécies, permitindo o uso racional da floresta (Mello e Varela, 2006).

A escolha das espécies arbóreas nativas visando o atendimento de um programa de reflorestamento ou florestamento apresenta uma série de dificuldades, pois essas espécies, além de pouco estudadas, apresentam dificuldades quanto à obtenção de mudas (Carvalho et al., 1980).

Não existem informações de trabalhos de pesquisa referentes à análise das sementes de Acacia caven. Assim, o objetivo desse trabalho foi avaliar tratamentos para superação da dormência tegumentar e a temperatura adequada para o teste de germinação de sementes de $A$. caven. 


\section{MATERIAL E MÉTODOS}

A pesquisa foi conduzida no Laboratório de Análise de Sementes da Pontifícia Universidade Católica do Rio Grande do Sul (PUCRS) - Campus Uruguaiana. Foram obtidas sementes de diversas árvores no Parque Estadual do Espinilho, no município da Barra do Quarai - RS, em janeiro de 2007. Os frutos foram coletados manualmente, diretamente das árvores, acondicionados em sacos de plástico. Os frutos foram enviados ao laboratório para secagem em estufa a $36^{\circ} \mathrm{C}$ (Silva et al., 1993) por 24 h, para obtenção das sementes que foram extraídas manualmente dos frutos, descartando-se as infectadas e de coloração preta. O teor de água das sementes foi determinado pelo método de estufa a $\quad 105^{\circ} \mathrm{C}$ por 24 $\mathrm{h}$, de acordo com as Regras para Análise de Sementes (Brasil, 1992).

Tratamentos para a Superação da Dormência: As sementes foram submetidas aos seguintes tratamentos: T1 testemunha, sementes intactas; T2 - imersão das sementes em água a $40^{\circ} \mathrm{C}$ por $24 \mathrm{~h}$ em estufa; T3 - imersão das sementes em hipoclorito de sódio a $0,5 \%$ por 24 h; T4 - escarificação mecânica: as sementes foram friccionadas manualmente com lixa d'água $\mathrm{n}^{\circ} .80$ até o desgaste visível do tegumento no lado oposto à micrópila e $\mathrm{T} 5$ - corte de $1,0 \mathrm{~mm}$, com o auxílio de um estilete, na região oposta à micrópila.

Nos tratamentos T4 e T5 as sementes ficaram imersas em água destilada por $3 \mathrm{~h}$ antes da semeadura, segundo recomendações de Brasil (1992).

Após os tratamentos de superação da dormência, as sementes foram submetidas ao teste de germinação, sobre papel germitest umedecido com água destilada em quantidade equivalente a 2,5 vezes a massa do papel não hidratado, em caixas de plástico transparentes e com tampa (11 x 3,5 x 3,5 $\mathrm{cm}$ ), acondicionadas em germinador Mangelsdorf a $20{ }^{\circ} \mathrm{C}$. A temperatura utilizada para a germinação das sementes, a data da primeira contagem e a duração do teste seguiram recomendações das Regras para Análise de Sementes (Brasil, 1992), para o gênero Acacia, pois não há prescrições para a espécie. Consideraram-se como plântulas normais, aquelas com comprimento mínimo de $3 \mathrm{~cm}$, compreendido entre a extremidade da radícula e a dobra do hipocótilo.

Germinação em diferentes temperaturas: os experimentos foram realizados após a desinfestação das sementes em solução de hipoclorito de sódio a $2 \%$ por 4 minutos, pré-embebição em água destilada por 5 minutos e lavagem em água corrente (Figliolia et al., 1993) e corte de $1,0 \mathrm{~mm}$, com o auxílio de um estilete, na região oposta à micrópila, para a superação da dormência. Os testes de germinação foram conduzidos em germinadores regulados para as temperaturas constantes de $20^{\circ} \mathrm{C}, 25^{\circ} \mathrm{C}$ e $30^{\circ} \mathrm{C}$, e fotoperíodo de $12 \mathrm{~h}$ obtido com lâmpada fluorescente de 20 $\mathrm{W}$, sobre papel germitest.

O critério de germinação foi o mesmo descrito anteriormente, no teste de superação da dormência. Para a determinação da data de realização da primeira contagem do teste de germinação, foi calculado o Tempo Médio de Germinação (TMG), recomendado por Edwards citado por Bonow (1984):

$$
D M G=\frac{N 1 d 1+N 2 d 2+\ldots . . N i d i}{N 1+N 2+\ldots . . N i}
$$

Em que: $\mathrm{Ni}=\mathrm{n}^{\circ}$ de sementes germinadas no dia $\mathrm{i} ; \mathrm{di}=$ unidade de tempo, em dias, do início do teste até a observação da germinação Ni.

A duração do teste de germinação foi determinada quando da estabilização da germinação, após serem retiradas do substrato todas as plântulas normais e anormais, restando no substrato apenas sementes mortas.

Utilizou-se o delineamento experimental inteiramente casualizado com quatro repetições de 50 sementes por tratamento. Os dados expressos em porcentagem foram transformados em arcseno $\sqrt{x / 100}$ e as médias comparadas pelo de teste de Tukey ao nível de $5 \%$ de probabilidade, contudo nas Tabelas os dados são apresentados sem transformação.

\section{RESULTADOS E DISCUSSÃO}

Os dados referentes aos tratamentos de superação da dormência das sementes de Acacia caven encontram-se na Tabela 1. Os maiores valores de germinação ocorreram nos tratamentos de escarificação mecânica (T4) e no corte de $1,0 \mathrm{~mm}$, com o auxílio de um estilete, na região oposta à micrópila (T5), sem diferença estatística entre eles. Resultados semelhantes foram obtidos por Ferreira et al. (1992) quando utilizaram corte na região oposta à micrópila, em sementes das espécies Acacia bonariensis Gill e Mimosa bimucronata (D.C.) O. Kuntze, por Bruno et al. (2001) em sementes de Mimosa caesalpiniafolia Benth., por Alves et al. (2004) em sementes de Bauhinia divaricata L. e por Martinelli-Seneme et al. (2006) em sementes de Bauhinia variegata.

Da mesma forma a escarificação mecânica foi empregada com eficiência na superação da dormência de sementes de Leucaena diversifolia (Schlecht.) Bentham K 156 (Bertalot e Nakagawa, 1998), de Cassia excelsa Scharad (Jeller e Perez, 1999), de Bauhinia monandra Britt. (Alves et al., 2000), de Adesmia DC. (Tedesco et al., 2000), de Acacia mearnsii Willd. (Roversi et al., 2002) e de Lotus subbflorus L. (Jacob Jr. et al., 2004). 
TABELA 1. Dados percentuais de germinação, plântulas anormais, sementes mortas e duras de espinilho (Acacia caven) ao final do teste de germinação conduzido a $20{ }^{\circ} \mathrm{C}$ e submetidas a diferentes tratamentos para a superação da dormência, no Laboratório de Análise de Sementes.

\begin{tabular}{lcccc}
\hline \multicolumn{1}{c}{ Tratamentos } & $\begin{array}{c}\text { Germinação } \\
(\%)\end{array}$ & Plântula Anormal (\%) & $\begin{array}{c}\text { Semente } \\
\text { Morta (\%) }\end{array}$ & $\begin{array}{c}\text { Semente Dura } \\
(\%)\end{array}$ \\
\hline Testemunha & $5,0 \mathrm{~b}$ & $1,0 \mathrm{c}$ & $12,0 \mathrm{a}$ & $82,0 \mathrm{a}$ \\
Água quente $\left(40^{\circ} \mathrm{C}\right)$ & $2,0 \mathrm{~b}$ & $1,0 \mathrm{c}$ & $17,0 \mathrm{a}$ & $80,0 \mathrm{a}$ \\
Hipoclorito de sódio & $1,0 \mathrm{~b}$ & $3,0 \mathrm{c}$ & $8,0 \mathrm{a}$ & $88,0 \mathrm{a}$ \\
Escarificação Mecânica & $63,0 \mathrm{a}$ & $20,0 \mathrm{a}$ & $17,0 \mathrm{a}$ & $0 \mathrm{~b}$ \\
Corte (oposto à micrópila) & $69,0 \mathrm{a}$ & $15,5 \mathrm{a}$ & $15,5 \mathrm{a}$ & $0 \mathrm{~b}$ \\
\hline Coef. de variação (\%) & 11,94 & 70,19 & 45,75 & 16.82 \\
\hline
\end{tabular}

Médias seguidas pela mesma letra, nas colunas, não diferem entre si pelo teste de Tukey a $5 \%$.

Ao final do teste, para os tratamentos T4 e T5 não houve sementes duras, o que comprova a eficácia dos mesmos na superação da dormência das sementes de $A$. caven (Tabela $1)$.

A porcentagem de germinação da testemunha (T1), embora tenha sido baixa, foi maior que os valores apresentados nos tratamentos com água quente a $40{ }^{\circ} \mathrm{C}$ por $24 \mathrm{~h}(\mathrm{~T} 2)$ e com hipoclorito de sódio a $0,5 \%$, por $24 \mathrm{~h}$ (T3), porém sem diferenças estatísticas entre os mesmos, o que demonstra que esses tratamentos não foram efetivos na superação da dormência das sementes de $A$. caven. Rodrigues et al. (1990) afirmam que embora a água fervente seja um método vantajoso pelo baixo custo, a mesma tem proporcionado resultados contraditórios na superação de dormência.

Em trabalhos de superação de dormência envolvendo diferentes tratamentos, aqueles com água quente foram os menos eficientes em vários experimentos conforme resultados obtidos por Perez e Prado (1993) com sementes de Copaifera langsdorfii Desf., por Santarém e Áquila (1995) com Senna macranthera (Colladon) Irwin \& Barneby, por Jeller e Perez (1999) com Cassia excelsa Schrad.e por Alves et al. (2000) com Bauhinia monandra Britt e Bauhinia ungulata L. Por outro lado, o tratamento com hipoclorito de sódio (T3) proporcionou a menor porcentagem de sementes mortas, por ser uma solução eficiente contra a ação de alguns microorganismos sobre as sementes.

A impermeabilidade do tegumento à água é uma das causas mais comuns da dormência das sementes de leguminosas (Popinigis, 1985). Essa característica é fundamental para a permanência da espécie em campo, quando as condições climáticas não são favoráveis para o estabelecimento da mesma. As sementes com tegumento impermeável à água podem permanecer viáveis no solo durante longo período de tempo, constituindo o banco de sementes. Algumas dessas sementes podem, em determinadas situações, embeberem água e germinarem em intervalos sucessivos, quando as condições ambientais forem favoráveis (Alves et al., 2004).

As médias da porcentagem de germinação, de plântulas anormais, de sementes mortas e duras, tempo médio de germinação e duração do teste, obtidas de sementes submetidas a diferentes temperaturas para germinação encontram-se na Tabela 2.

Embora sem diferença estatística na porcentagem final de germinação entre as três temperaturas, a duração do teste de germinação foi menor a $30{ }^{\circ} \mathrm{C}$. Segundo Tillmann et al. (2003), a temperatura ótima para o teste de germinação é aquela em que se obtém maior porcentagem de germinação em menor espaço de tempo.

Figueiredo e Popinigis (1980) testaram diferentes temperaturas para os testes de germinação de sementes de Urena lobata L. e concluíram que a $30{ }^{\circ} \mathrm{C}$ houve maior porcentagem de plântulas normais. Resultados semelhantes foram relatados por Martinelli-Seneme et al. (2006) com sementes de Bauhinia variegata $\mathrm{L}$.

A porcentagem e o índice de velocidade de germinação das sementes de Parkia platycephala Benth foram maiores a $30{ }^{\circ} \mathrm{C}$, comparativamente aos resultados obtidos a $25^{\circ} \mathrm{C}$ e 20 ${ }^{\circ} \mathrm{C}$ (Nascimento et al., 2003).

Os resultados para plântulas anormais e sementes mortas (Tabela 2), foram semelhantes nas três temperaturas. Também não foram observadas sementes duras, independentemente da temperatura testada, o que comprova a eficiência do tratamento para superação da dormência das sementes. 
TABELA 2. Porcentagem média de germinação, de plântulas anormais, de sementes mortas e duras, tempo médio (TMG) e duração do teste de germinação de sementes de Acacia caven, nas temperaturas de $20^{\circ} \mathrm{C}, 25^{\circ} \mathrm{C}$ e $30{ }^{\circ} \mathrm{C}$ e fotoperíodo de 12 horas.

\begin{tabular}{ccccccc}
\hline $\begin{array}{c}\text { Temperaturas } \\
\left({ }^{\circ} \mathrm{C}\right)\end{array}$ & $\begin{array}{c}\text { Germinação } \\
(\%)\end{array}$ & $\begin{array}{c}\text { Plântula } \\
\text { Anormal (\%) }\end{array}$ & $\begin{array}{c}\text { Semente } \\
\text { Morta (\%) }\end{array}$ & $\begin{array}{c}\text { Semente } \\
\text { Dura (\%) }\end{array}$ & $\begin{array}{c}\text { TMG } \\
(\text { dias })\end{array}$ & $\begin{array}{c}\text { Duração do } \\
\text { teste (dias) }\end{array}$ \\
\hline $20^{\circ} \mathrm{C}$ & $72 \mathrm{a}$ & $24 \mathrm{a}$ & $04 \mathrm{a}$ & $0 \mathrm{a}$ & $13,86 \mathrm{a}$ & 19 \\
$25^{\circ} \mathrm{C}$ & $63 \mathrm{a}$ & $23 \mathrm{a}$ & $14 \mathrm{a}$ & $0 \mathrm{a}$ & $9,36 \mathrm{~b}$ & 15 \\
$30^{\circ} \mathrm{C}$ & $71 \mathrm{a}$ & $15 \mathrm{a}$ & $14 \mathrm{a}$ & $0 \mathrm{a}$ & $4,81 \mathrm{c}$ & 7 \\
\hline Coef. de variação (\%) & 9,90 & 34,77 & 49,04 & 0 & 7,63 & - \\
\hline
\end{tabular}

Médias seguidas pela mesma letra, nas colunas, não diferem entre si pelo teste de Tukey a $5 \%$.

O tempo médio de germinação (TMG) foi influenciado pela temperatura, apresentando uma germinação mais rápida (5 dias) na temperatura de $30^{\circ} \mathrm{C}$ (Tabela 2). Nas temperaturas mais baixas $\left(20^{\circ} \mathrm{C} \mathrm{e} 25^{\circ} \mathrm{C}\right)$, o processo germinativo foi mais lento, havendo diferença estatística entre o três tratamentos. Conforme Carvalho e Nakagawa (2000), as baixas temperaturas reduzem a velocidade de germinação e alteram a uniformidade de emergência das plântulas.

Assim, a $30{ }^{\circ} \mathrm{C}$ a germinação iniciou mais cedo, o mesmo ocorrendo com a formação de plântulas normais. Isto fez com que o teste fosse finalizado num menor período, comparado aos testes nas temperaturas de $20{ }^{\circ} \mathrm{C}$ e $25{ }^{\circ} \mathrm{C}$. A primeira contagem de germinação pode ser realizada no quinto dia e o encerramento do teste após sete dias da instalação do mesmo, para a temperatura de $30^{\circ} \mathrm{C}$.

\section{CONCLUSÕES}

A dormência das sementes de Acacia caven por impermeabilidade do tegumento à água pode ser superada com corte ou por escarificação mecânica, ambos na região oposta à micrópila.

A temperatura de $30^{\circ} \mathrm{C}$ é adequada para a condução do teste de germinação de sementes de Acacia caven, com a primeira contagem da germinação realizada aos cinco dias e o encerramento do teste com sete dias.

\section{REFERÊNCIAS}

ALVES, A.U.; DORNELAS, C.S.M.; BRUNO, R.L.A.; ANDRADE, L.A.; ALVES, E.U.; Superação da dormência em sementes de Bauhinia divaricata L. Acta Botanica Brasilica, v.18, n.4, p.871-879, 2004.

ALVES, M.C.S.; MEDEIROS-FILHO, S.; ANDRADENETO, M.; TEÓFILO, E. M. Superação da dormência de sementes de Bauhinia monandra Britt. e Bauhinia ungulata
L. - Caesalpinoideae. Revista Brasileira de Sementes, v.22, n.2, p.139-144, 2000.

BERTALOT, M.J.; NAKAGAWA, J. Superação da dormência em sementes de Leucaena diversifolia (Schlecht.) Bentham K 156. Revista Brasileira de Sementes, v.20, n.1, p.39-42, 1998.

BONOW, R.N. Estabelecimento de métodos de análise para a espécie trevo vesiculoso (Trifolium vesiculosum Savi). 1984. 68f. Tese (Mestrado em Análise de Sementes) - Faculdade de Agronomia, Universidade Federal de Pelotas, Pelotas, 1984.

BORGES, E.E.L.; BORGES, R.C.G.; CANDIDO, J.F.; GOMES, J.M. Comparação de métodos de quebra de dormência em sementes de copaíba. Revista Brasileira de Sementes, v.4, n.1, p.9-12, 1982.

BRASIL. Ministério da Agricultura e Reforma Agrária. Secretaria Nacional de Defesa Agropecuária. Departamento Nacional de Defesa Vegetal. Coordenação de Laboratório Vegetal. Regras para análise de sementes. Brasília, DF, 1992. 365p.

BRUNO, R.L.A.; ALVES E.U.; OLIVEIRA, A.P.; PAULA, R.C. Tratamentos pré-germinativos para superar a dormência de sementes de Mimosa caesalpiniaefolia Benth. Revista Brasileira de Sementes, v.23, n.2, p.136-143, 2001.

CARVALHO, N.M.; NAKAGAWA, J. Sementes: ciência, tecnologia e produção. 4.ed. Jaboticabal: FUNEP, 2000. $588 \mathrm{p}$.

CARVALHO, N.M.; SOUZA FILHO, J.F.; GRAZIANO, T.T.; AGUIAR, I.B. Maturação fisiológica de sementes de amendoim-do-campo. Revista Brasileira de Sementes, v.2, n.2, p.23-28, 1980.

CAVADA, B.S.; SANTI, T.; GADELHA, C.A.A.; GRANGEIRO, T.B.; NETO, M.A.; NUNES, E.P.; GALVANI, F.R. Bases quimiotaxonômicas para a diferenciação dos táxons Acacia caven (Mol.) Mol e Acacia farnesiana (L.) 
Willdenow (LEGUMINOSAE, MIMOSOIDEAE). Revista da Faculdade de Zootecnia, Veterinária e Agronomia, v.2/3, n.1, p.78-83, dez /jan.1995/1996.

CORREA, M.P. Dicionário das plantas úteis do Brasil e exógenas cultivadas. Rio de Janeiro: Imprensa Nacional, v.1, 1984. 646p.

FERREIRA, A.G.; JOÃO, K.H.L.; HEUSER, E.D. Efeitos de escarificação sobre a germinação e do $\mathrm{pH}$ no crescimento de Acacia bonariensis Gill e Mimosa bimucronata (D.C.) O.K. Revista Brasileira de Fisiologia Vegetal, v.4, n.1, p.63-65, 1992.

FIGLIOLIA, M.B.; OLIVEIRA, E.C.; PIÑA-RODRIGUES, F.M.C. Análise de Sementes. In: AGUIAR, I.B.; PIÑARODRIGUES, F.C.M.; FIGLIOLIA, M.B. (Coord.). Sementes Florestais Tropicais. Brasília, DF: ABRATES, 1993. p.137-174.

FIGUEIREDO, F.J.C.; POPINIGIS, F. Temperatura de germinação para sementes de malva. Revista Brasileira de Sementes, v.2, n. 2, p.9-22, 1980.

JACOB JUNIOR, E.A.; MENEGHELLO, G.E.; MELO, P.T.B.S.; MAIA, M.S. Tratamentos para superação da dormência em sementes de Cornichão Anual. Revista Brasileira de Sementes, v.26, n.2, p.15-19, 2004.

JELLER, H.; PEREZ, S.C.J.G.A. Estudo da superação da dormência e da temperatura em sementes de Cassia excelsa Schrad. Revista Brasileira de Sementes, v.21, n.1, p.32-40, 1999.

JOFFRE, R.; VACHER, J.; LLANOS, C.; LONG, G. The dehesa: an agrosilvopastoril system of the Mediterranean region with special reference to the Sierra Morena area of Spain. Agroforestry Systems, v.6, p.71-96, 1988.

LEDO, A.A. Produção de sementes, mudas e tratos culturais em essências florestais para reflorestamento e arborização. Recife: UFRPE, 1979. 113p.

MARCHIORI, J.N.C. Anatomia da madeira e casca do Espinilho - Acacia caven (Mol.) Mol. Ciência Florestal, v.2, n.1, p.27-47, 1992.

MARTINELLI-SENEME, A.; POSSAMAI, E.; SCHUTA, L.R.; VANZOLINI, S. Germinação e sanidade de sementes de Bauhinia variegata. Revista Árvore, v.30, n.5, p.719724, 2006.

MELLO, M.F.F.; VARELA, V.P. Aspectos morfológicos de frutos, sementes, germinação e plântulas de duas espécies florestais da Amazônia: I. Dinizia excelsa Ducke (AngelimPedra). II Cedrelinga catenaeformis Ducke (Cedrorana) - Leguminosae: Mimosoideae. Revista Brasileira de Sementes, v.28, n.1, p.54-62, 2006.

NASCIMENTO, W.M.O.; RAMOS, N.P.; CARPI, V.A.F.;
SCARPARE FILHO, J.A.; CRUZ, E.D. Temperatura e substrato para germinação de sementes de Parkia platycephala Benth. (Leguminoseae - Mimosoideae). Revista Agricultura Tropical, v.7, n.1, p.119-129, 2003. Disponível em: <http:// www.ufmt.br/agtrop/revista $7 /$ doc/10.htm>. Acesso em: 05 jun. 2007.

OVALLE, C.; AVENDAÑO, J. Utilización silvopastoral del espinal. II. Influencia del espino (Acacia caven (Mol.) Hook et Arn.) sobre algunos elementos del medio. Agricultura Técnica, v.44, n.4, p.353-362, 1984.

PEREZ, S.C.J.G.A.; PRADO, C.H.B.A. Efeitos de diferentes tratamentos pré-germinativos e da concentração de alumínio no processo germinativo de sementes de Copaifera langsdorfi. Revista Brasileira de Sementes, v.15, n.1, p.115-118, 1993.

POPINIGIS, F. Fisiologia de sementes. 2. ed. Brasília, DF: AGIPLAN, 1985. 289p.

RAMBO, B. Leguminosas riograndenses. Pesquisas - Série Botânica, n.23, 1966. p.166.

RODRIGUES, E.H.A.; AGUIAR, I.B.; SADER, R. Quebra de dormência de sementes de três espécies do gênero Cassia. Revista Brasileira de Sementes, v.12, n.12, p.17-27, 1990.

ROVERSI, T.; MATTEI, V.L.; SILVEIRA, J.P.; FALCK, G.L.; Superação da dormência em sementes de Acacia negra (Acacia mearnsii Willd.). Revista Brasileira Agrociência, v.8, n.2, p.161-163, 2002.

SANTARÉM, E.R.; ÁQUILA, M.E.A. Influência de métodos de superação de dormência e do armazenamento na germinação de sementes de Senna mancranthera (Colladon) Irwin \& Barneby (Leguminosae). Revista Brasileira de Sementes, v.17, n.2, p.205-209, 1995.

SANTOS, S.R.G.; AGUIAR, I.B. Germinação de sementes de branquilho (Sebastiania commersoniana (Baill.) Smith \& Downs) em função do substrato e do regime de temperatura. Revista Brasileira de Sementes, v.22, n.1, p.120-126, 2000.

SARAIVA, D.D.; SOUSA, K.S.;SOUZA, C.A.; SALENGUE, E.V. Recuperação de Mosaicos Vegetacionais no Bioma Campos Sulinos, RS/BRASIL. <Disponível em: <http:// www.ufpel.edu.br/cic/2005/arquivos/CB_00596.rtf.>. Acesso em: 13 nov. 2009.

SILVA, A.; FIGLIOLIA, M.B.; AGUIAR, I.B. Secagem, extração e beneficiamento de sementes. In: AGUIAR, I.B.; PIÑA-RODRIGUES, F.C.M.; FIGLIOLIA, M.B. (Coord.). Sementes Florestais Tropicais. Brasília, DF: ABRATES, 1993. p.303-330.

TEDESCO, S.B.; STEFANELLO, M.O.; SCHIFINOWITTMAN, M.T.; BATTISTIN, A.; DALL'AGNOL, M. Superação de dormência em sementes de espécies de Adesmia 
DC. (Leguminosae). Revista Brasileira de Agrociência, v.7, n.2, p.89-92, 2000.

TILLMANN, M.A.E.; MELLO, V.D.C.; ROTA, G.R.M. Análise de sementes. In: PESKE, S.T.; ROSENTHAL, M.D.; ROTTA, G.R.M. Sementes: fundamentos científicos e tecnológicos. Pelotas: Editora e Gráfica Universitária, 2003. p.140-224.

TORRES, S.B.; SANTOS, S.S.B. Superação da dormência em sementes de Acacia senegal (L.) Willd. e Parkinsonia aculeata L. Revista Brasileira de Sementes, v.13, n.2, p.5457, 1994.

TREJO, J.A.V.; GARCIA, J.C.C.; CASTAÑEDA, H.J.A.; IBRAHIM, M. Mejoramiento del suelo por Acacia mangium en un sistema silvopastoril con Brachiaria humidicola. Disponível em: < http://www.fao.org/ag/AGa/AGAP/FRG/ AFRIS/espanol/Document/AGROF99/Velasco.htm>. Acesso em: 13 nov. 2009. 